\title{
Research on the Hydrate Formation in the process of Gas Phase $\mathrm{CO}_{2}$ Pipeline Transportation
}

\author{
Y. D. Zhang ${ }^{1,2 *}$, D. Wang ${ }^{1}$, J. P. Yang ${ }^{2}$, Lei Tian ${ }^{1}$ and Lijuan $\mathrm{Wu}^{1}$ \\ ${ }^{* 1}$ Key Laboratory of Oil Gas Production, Research Center of Yangtze University and China \\ National Petroleum Corporation, Yangtze University, Wuhan, Hubei 430100, China \\ 2 SAGD Development Project Management Department of Liaohe Oilfield Company, PetroChina, \\ Panjin, Liaoning 124000, China
}

Email: zhangyindihust@foxmail.com.

\begin{abstract}
With the development of the third oil recovery in oil fields and $\mathrm{CO}_{2}$ capture, utilization and storage (CCUS) technology, $\mathrm{CO}_{2}$ injection has become an effective means to enhance oil recovery (EOR) and relieve the greenhouse gas effect. The $\mathrm{CO}_{2}$ pipeline transportation technology started relatively late in China, where the gas phase and liquid phase transportation are widely used methods. The $\mathrm{CO}_{2}$ hydrate formation in the process of transportation may reduce the valve, destroy the equipment and even cause pipeline ice blockage, but research in China on $\mathrm{CO}_{2}$ hydrate is not very extensive. In this paper, the $\mathrm{CO}_{2}$ hydrate formation conditions were simulated using HYSYS, and the simulation results were compared with the experimental results to verify the feasibility of the simulation method. Based on this, factors in the influence of gas impurities on $\mathrm{CO}_{2}$ hydrate formation are simulated, and the pipeline transportation process of $\mathrm{CO}_{2}$ hydrate formation are predicted. The results show that when there is a low amount of impurity content, the gaseous impurities such as $\mathrm{CH}_{4}, \mathrm{~N}_{2}, \mathrm{H}_{2}, \mathrm{O}_{2}$, have little effect on $\mathrm{CO}_{2}$ hydrate formation in gaseous $\mathrm{CO}_{2}$ pipeline transport. Furthermore, environmental temperature has little effect on the changes in pipeline pressure along the transport route. However, with a change in environment temperature, temperature along the pipeline changes greatly. $\mathrm{CO}_{2}$ will change from a gas state to a liquid state in the pipeline when the ambient temperature is low. In the case of low ambient temperature, a thick insulation layer should be used, and heating of the pipeline may also be required. When the ambient temperature is higher than about $10^{\circ} \mathrm{C}$, there will be no hydrates formed in the pipeline.
\end{abstract}

Keywords: Gaseous $\mathrm{CO}_{2}$, Pipeline Transportation, Hydrate, HYSYS Simulation.

\section{INTRODUCTION}

The greenhouse effect and global warming are the focus of current energy and environmental issues, and great emphasis has been attached on the problem of reducing $\mathrm{CO}_{2}$ emissions. Recently, research has strenghtened on $\mathrm{CO}_{2}$ carbon capture, utilization and storage (CCUS), transportation and enhanced oil recovery technology in various countries globally [1-3]. For example, the Jiangsu FuMing area has applied natural carbon dioxide gas to oil exploitation and achieved great economic benefits and has improved the efficiency of oil recovery in the process [4]. China began to build the $\mathrm{CO}_{2}$ long distance pipeline in the beginning of the 1970s, and the $\mathrm{CO}_{2}$ was transported from the $\mathrm{CO}_{2}$ gas fields and other gas sources (such as natural gas purification plants) to the corresponding oil field for the third exploitation to improve the oil recovery. It has been proved that there are abundant $\mathrm{CO}_{2}$ resources and very large $\mathrm{CO}_{2}$ consumption potential in China, but there is no practical experience of construction in China on a large-scale industrial $\mathrm{CO}_{2}$ pipeline system. Furthermore, there is still a long way to go in the study of design, construction and operation of $\mathrm{CO}_{2}$ in the long distance pipeline transportation system, and the related technology involved during the management are only in the initial stages compared with other countries [5]. The main delivery methods are the gas phase and the liquid phase in the process of $\mathrm{CO}_{2}$ transportation in our country. Currently, there is much research globally on the hydrate experimental test, formation conditions and inhibiting methods of thermodynamics, and formation and decomposition dynamics of hydrate, but they are all mainly concentrated on the conventional natural gas hydrate research, eith little research results on $\mathrm{CO}_{2}$ gas hydrate formation conditions. Therefore, it is necessary to carry out related research.

\section{THE PHYSICAL PROPERTIES OF $\mathrm{CO}_{2}$}

$\mathrm{CO}_{2}$ is a colorless and odorless gas which is soluble in water in normal conditions, and because it has a higher density air, the diffusion rate is slow, and it is in the form of a gas in normal temperature and pressure [6]. The phase state is 
divided into the following five regions: gas, general liquid, solid, dense phase and supercritical fluid. The triple point of $\mathrm{CO}_{2}$ appears at $-56^{\circ} \mathrm{C}$ and $0.52 \mathrm{Mpa}$ and the critical point appears at $31.4^{\circ} \mathrm{C}$ and $7.38 \mathrm{MPa}$, as shown in Figure 1 .

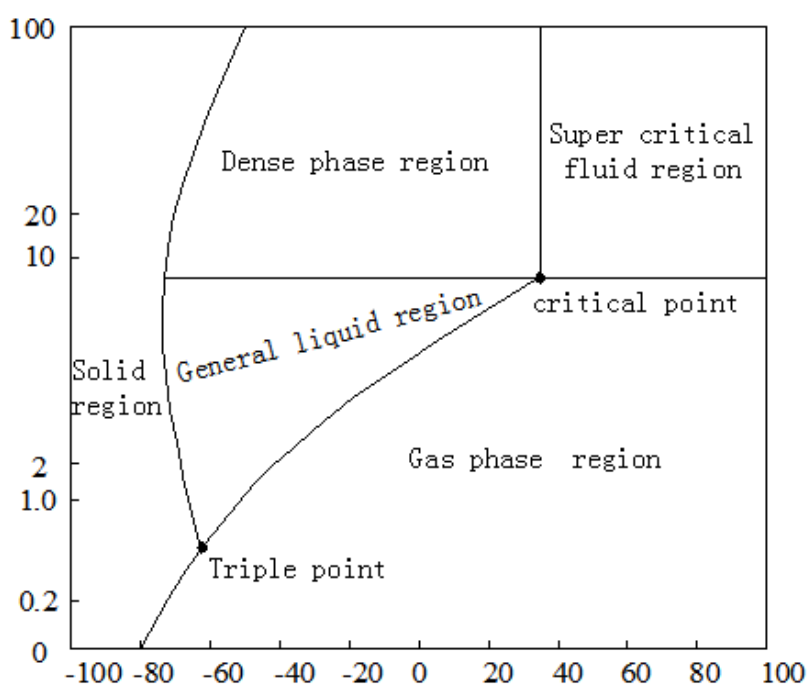

Figure 1. $\mathrm{CO}_{2}$ phase diagram

$\mathrm{CO}_{2}$ hydrate is a non-stoichiometric cage-type crystal compound produced by $\mathrm{CO}_{2}$ gas and water under a certain temperature and pressure conditions. The density of hydrate is about $0.88-0.929 / \mathrm{cm}^{3}$.

If the hydrate forms in the pipeline, it will cause blockage in the pipeline, the transmission capacity to fall, increase the pipeline friction loss, damage the along conveyor equipment, and may even lead to pipeline failure.

Low temperature and high pressure are the two necessary conditions for hydrate formation [7-8]. Certain thermodynamic conditions are needed for the formation of $\mathrm{CO}_{2}$ in the pipeline and the formation of free water is the necessary condition. The nucleation of hydrate will be continuously increased and form dense $\mathrm{CO}_{2}$ hydrate, and thus blocking the pipeline.

\section{FEASIBILITY ANALYSIS OF SIMULATION METHOD}

\subsection{The selection of state equation}

HYSYS software was used to simulate the hydrate formation conditions of $\mathrm{CO}_{2}$, and the P-R state equation was selected in the simulation process, which was proposed by Peng-Robinson in 1976.

$$
\begin{aligned}
& p=\frac{R T}{V-b}-\frac{a(T)}{V(V+b)+b(V-b)} \\
& a(T)=a\left(T_{c}\right) \alpha\left(T_{r}, \omega\right)
\end{aligned}
$$

$$
a\left(T_{c}\right)=0.45724 \frac{R^{2} T_{c}^{2}}{p_{c}}
$$

$$
b=0.07780 \frac{R T_{c}}{p_{c}}
$$

$$
\sqrt{\alpha}=1+m\left[1-\left(\frac{T}{T_{c}}\right)^{0.5}\right]
$$

$m=0.37464+1.54226 \omega-0.26992 \omega^{2}$

Type: $p$ - system pressure, $\mathrm{kPa}$.

$V$ - molar volume, $\mathrm{m}^{3} / \mathrm{mol}$.

$R$ - universal gas constant, $8.3143 \mathrm{~kJ} /(\mathrm{kmol} / \mathrm{k})$.

$p_{c}$-critical pressure, $\mathrm{kPa}$.

$T$ - system temperature, $\mathrm{K}$.

$T_{c}$ - critical temperature, $\mathrm{K}$.

$T_{r}$ - contrast gas temperature; $T_{r}=T / T_{c}$.

$\omega$ - eccentric factor (the eccentric factor of $\mathrm{CO}_{2}$ is $0.225)$.

\subsection{Comparison of simulation results with experimental values}

Hui Jian used the hydrate prediction experiment to conduct the hydrate prediction on different gas components. The experiment was conducted at the National Key Laboratory which named "Oil and Gas Reservoir Geology and Development Engineering" of Southwest Petroleum University. Isobaric cooling method was used to study the hydrate formation thermodynamic conditions in the process of the experiment [4]. In this paper, HYSYS software is used to simulate the corresponding working conditions, and the results are compared with the experimental results, as shown in Figure 2 and Table 1.

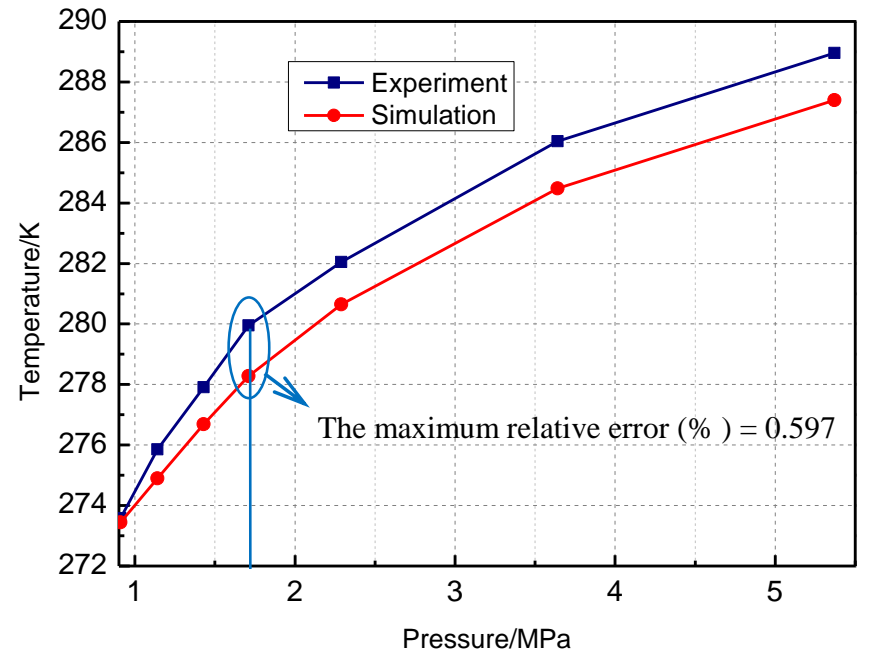

Figure 2. Formation temperature of hydrocarbon gas hydrate without $\mathrm{CO}_{2}$

The formation temperature of hydrocarbon gas hydrate without $\mathrm{CO}_{2}$ is shown in Figure 2. When the pressure range is between $0.91 \mathrm{Mpa}$ and $5.37 \mathrm{Mpa}$, the maximum relative error rate between the experimental temperature and the simulated temperature is $0.597 \%$. 
Table 1. Mixed gas hydrate of $\mathrm{CO}_{2}$ and $\mathrm{CH}_{4}$ formation conditions

\begin{tabular}{lllll}
\hline $\begin{array}{l}\text { Experimental } \\
\text { pressure/MPa }\end{array}$ & $\mathrm{CO}_{2} / \%$ & $\begin{array}{l}\text { Experimental } \\
\text { temperature } \\
\text { of hydrate/K }\end{array}$ & $\begin{array}{l}\text { Simulated } \\
\text { hydrate } \\
\text { formation } \\
\text { temperature } \\
/ \mathrm{K}\end{array}$ & $\begin{array}{l}\text { Relative } \\
\text { error } \%\end{array}$ \\
\hline 3.10 & 9 & 275.8 & 275.65 & 0.054 \\
\hline 2.52 & 10 & 273.7 & 272.59 & 0.406 \\
\hline 2.59 & 14 & 274.6 & 273.96 & 0.232 \\
\hline 2.12 & 25 & 273.8 & 273.79 & 0.005 \\
\hline 2.08 & 70 & 276.4 & 274.52 & 0.682 \\
\hline 1.45 & 79 & 273.7 & 272.70 & 0.365 \\
\hline 2.25 & 100 & 278.5 & 277.85 & 0.233 \\
\hline
\end{tabular}

The conditions for the formation of mixed gas hydrate of $\mathrm{CO}_{2}$ and $\mathrm{CH}_{4}$ is shown in Table 1. When the pressure range is between 1.45 Mpa and 3.10 Mpa for different content of $\mathrm{CO}_{2}$, the maximum relative error rate between the experimental temperature and the simulated temperature is $0.682 \%$.

By analysis and comparison of the experimental data and simulation data above, it is shown that using the P-R state equation in HYSYS to simulate the formation of $\mathrm{CO}_{2}$ hydrate is very feasible.

\section{EFFECTS OF IMPURITIES ON THE HYDRATE FORMATION IN CO 2 GASEOUS TRANSPORTATION}

The formation of hydrate in the $\mathrm{CO}_{2}$ pipeline is similar to natural gas. $\mathrm{CO}_{2}$ has some impurities such as $\mathrm{CH}_{4}, \mathrm{H}_{2} \mathrm{~S}, \mathrm{~N}_{2}, \mathrm{Ar}$, $\mathrm{O}_{2}, \mathrm{H}_{2}$, and heavier hydrocarbons $\left(\mathrm{C}_{2} \mathrm{H}_{6}\right.$ and $\mathrm{C}_{3} \mathrm{H}_{8}$, etc.) can also form hydrates [9-11]. Because the pressure in the process of $\mathrm{CO}_{2}$ gas conveying is under $4.8 \mathrm{MPa}$, it therefore selects $4.5 \mathrm{MPa}$ as the maximum pressure of the $\mathrm{CO}_{2}$ hydrate formation conditions simulation. HYSYS software is used to simulate $\mathrm{CO}_{2}$ hydrate formation conditions when several impurities are present such as $\mathrm{CH}_{4}, \mathrm{~N}_{2}, \mathrm{H}_{2}, \mathrm{O}_{2}$ in the molar percentage of $0 \%, 5 \%, 10 \%, 15 \%, 20 \%$. The simulation results are shown in Figures 3 to 6.

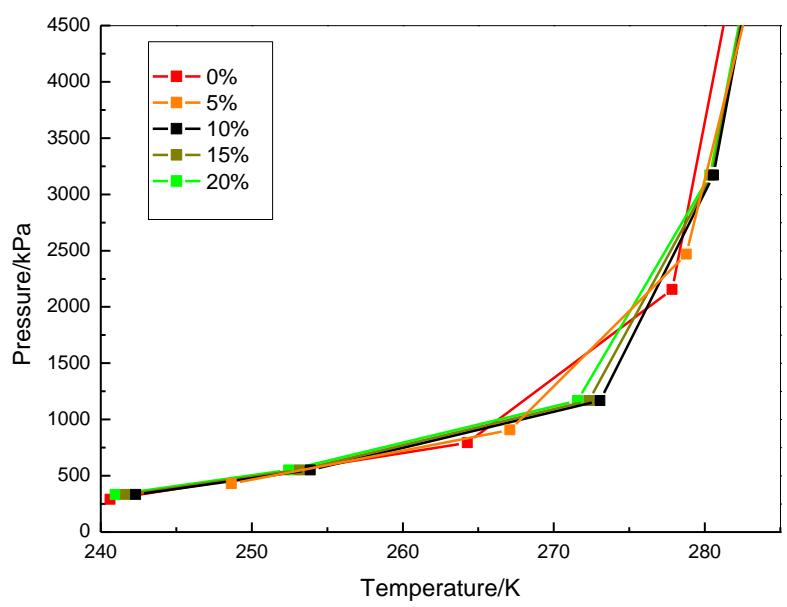

Figure 3. Effect of $\mathrm{CH}_{4}$ content on the hydrate formation

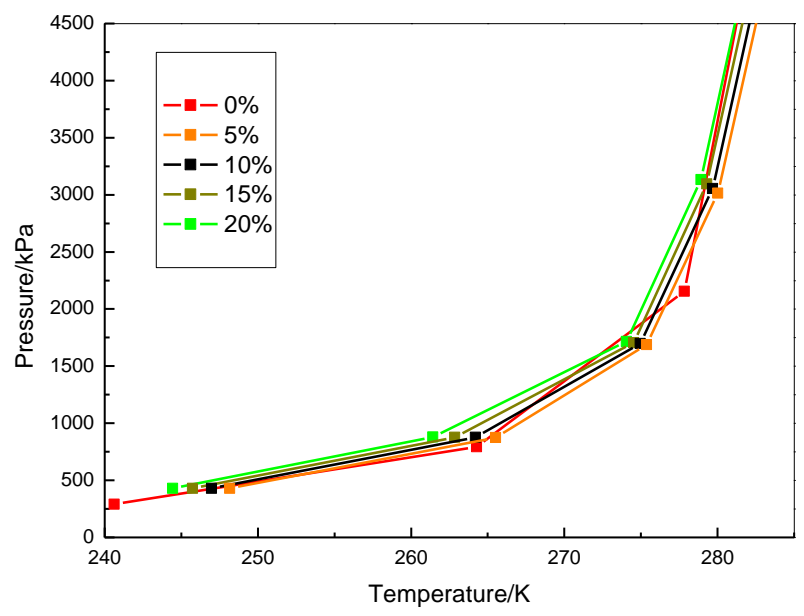

Figure 4. Effect of $\mathrm{N}_{2}$ content on the hydrate formation

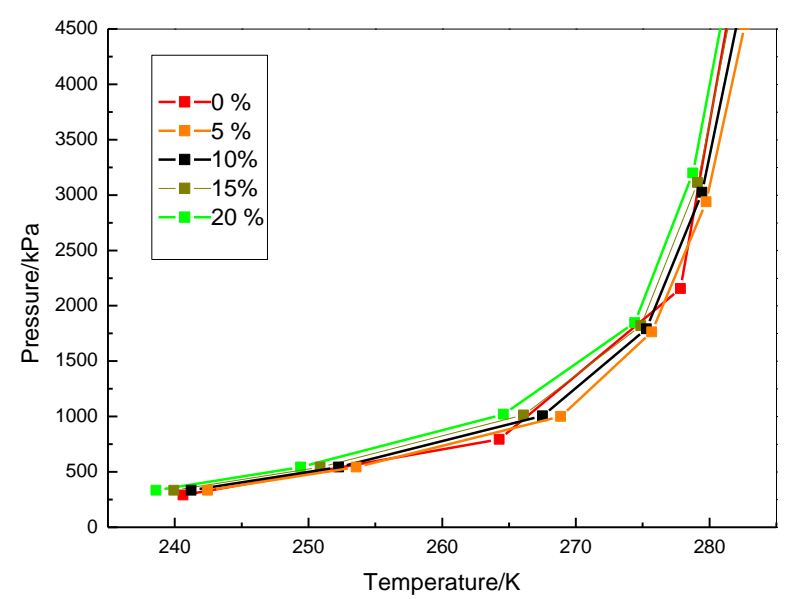

Figure 5. Effect of $\mathrm{H}_{2}$ content on the hydrate formation

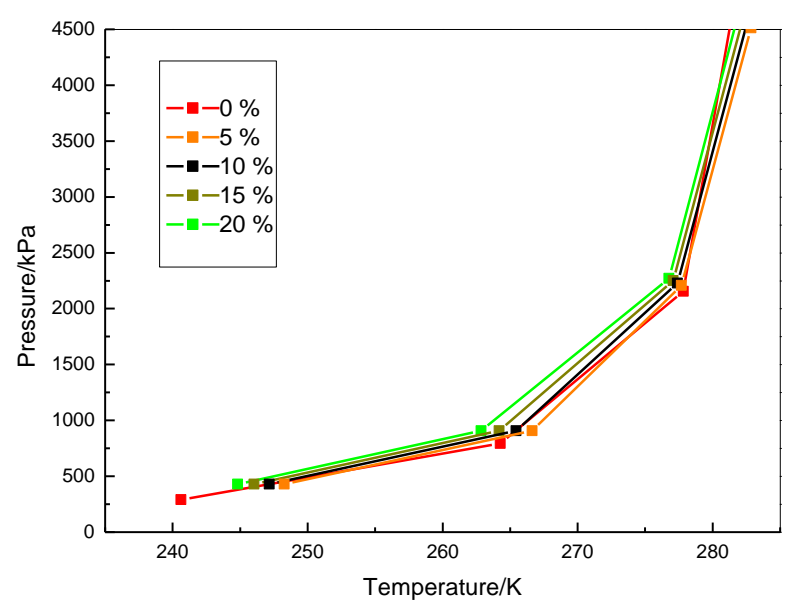

Figure 6. Effect of $\mathrm{O}_{2}$ content on the hydrate formation

The above figures show that small amounts of impurities have little effect on the $\mathrm{CO}_{2}$ hydrate formation. When the pipeline transport pressure is between $3.5 \mathrm{Mpa}$ and $4.5 \mathrm{Mpa}$, a small amount of impurities will slightly increase the temperature at which $\mathrm{CO}_{2}$ hydrate forms, and the $\mathrm{CO}_{2}$ hydrate formation temperature is about $10^{\circ} \mathrm{C}$. 


\section{SIMULATION OF GAS HYDRATE FORMATION IN

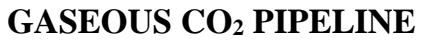

Generally, there are three methods for transporting $\mathrm{CO}_{2}$ : tanker transportation, ship transportation, and pipeline transportation. The quantity of tanker transportation is small and the cost is the highest among the three kinds of transportation. It is suitable for short distances, small volumes and is commonly used in $\mathrm{CO}_{2}$ flooding field experiments in small oil field. Ship transportation is applicable to the areas of the seas and rivers, and the $\mathrm{CO}_{2}$ storage equipment must be able to bear high pressure and/or low temperature. Pipeline transportation is suitable for long distances, with a large capacity and stable flow of directional transmission with a low cost for the average unit of transportation. However, its initial investment is large and the pipeline operation and maintenance requires that the operators must have much experience. According to previous research and practical application, pipeline transportation is the best choice for large scale and long distance $\mathrm{CO}_{2}$ transportation in both inland and offshore.

Pipeline transportation is the main way for transporting $\mathrm{CO}_{2}$ and natural gas containing $\mathrm{CO}_{2}$. The ways of pipeline transportation can be divided into gas phase, liquid phase and super critical transportation according to the phase of the medium. According to statistics, there are about $3100 \mathrm{~km} \mathrm{CO}_{2}$ pipeline in the world, its total throughput reaches $44 \mathrm{Mt} / \mathrm{a}$, and super critical transmission technology is mainly used. The majority of $\mathrm{CO}_{2}$ pipelines in the world are built in the western United States, and the total length is more than $2500 \mathrm{~km}$. Additionally, there is a total length of nearly $200 \mathrm{~km} \mathrm{CO}$ pipelines in Canada, Norway and Turkey. The $\mathrm{CO}_{2}$ pipeline transportation technology of China started relatively late and there is no mature long-distance transport pipeline. Only individual oil fields use the advantage of being close to $\mathrm{CO}_{2}$ gas source point to transport $\mathrm{CO}_{2}$. It uses gas or liquid pipeline to transport $\mathrm{CO}_{2}$ into the injection well to improve the oil recovery, such as the Jiangsu oilfield and Jilin oilfield, etc.

Gas $\mathrm{CO}_{2}$ pipeline transportation technology is shown in Figure. 7. $\mathrm{CO}_{2}$ maintains the gas phase during the transportation, and its transmission pressure is increased by the compressor. Thermodynamic calculation is used to determine whether thick insulation is needed to be installed in pipeline. For $\mathrm{CO} 2$ gas wells, the extraction of gas is mainly in supercritical state. In order to meet the requirements of pipeline transportation, the gas must be throttled to reduce the pressure before entering the pipeline. In order to avoid getting into the supercritical state, the pressure cannot be too high when pressurizing $\mathrm{CO}_{2}$ gas. Although the higher the initial pressure of the gas phase transportation, the lower the energy consumption, there are potential risks of phase transition when the gas transmission pressure is too high. For example, the maximum operating pressure for a low pressure gas pipeline should not exceed $4.8 \mathrm{MPa}$ in the alternative plans for SACROC carbon dioxide pipeline transportation in the United States [12].

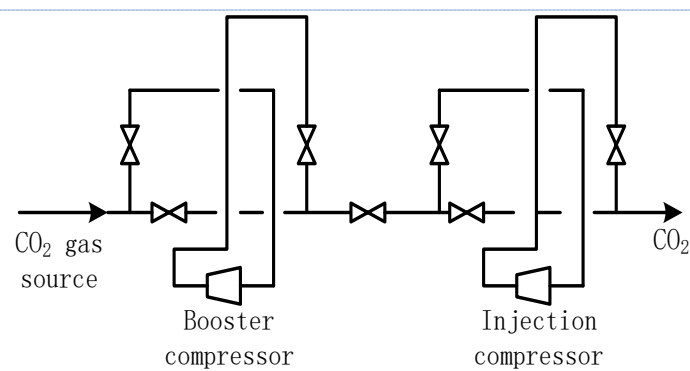

Figure 7. Gas $\mathrm{CO}_{2}$ pipeline transportation technology

\subsection{The simulation of parameters for $\mathrm{CO}_{2}$ pipeline transportation in HYSYS}

Selecting the parameters as shown in Tables 2 and 3 for pipeline transportation simulation.

Table 2. Physical parameters of gas

\begin{tabular}{cccc}
\hline Component & $\mathrm{CO}_{2}$ & $\mathrm{CH}_{4}$ & $\mathrm{~N}_{2}$ \\
\hline Mole fraction/\% & $96.1 \%$ & $3.5 \%$ & $0.4 \%$ \\
\hline
\end{tabular}

Table 3. Transportation conditions of pipelines

\begin{tabular}{lccc}
\hline $\begin{array}{l}\text { Internal } \\
\text { diameter/ } \\
\mathrm{mm}\end{array}$ & $\begin{array}{c}\text { Wall } \\
\text { thickness/m } \\
\mathrm{m}\end{array}$ & $\begin{array}{c}\text { External } \\
\text { diameter/m } \\
\mathrm{m}\end{array}$ & $\begin{array}{c}\text { Total heat transfer } \\
\text { coefficient/ } \\
\mathrm{W} /\left(\mathrm{m}^{2} \cdot{ }^{\circ} \mathrm{C}\right)\end{array}$ \\
\hline 365 & 6 & 377 & 1 \\
\hline
\end{tabular}

The pipeline transportation of the HYSYS model is shown in Figure 8.

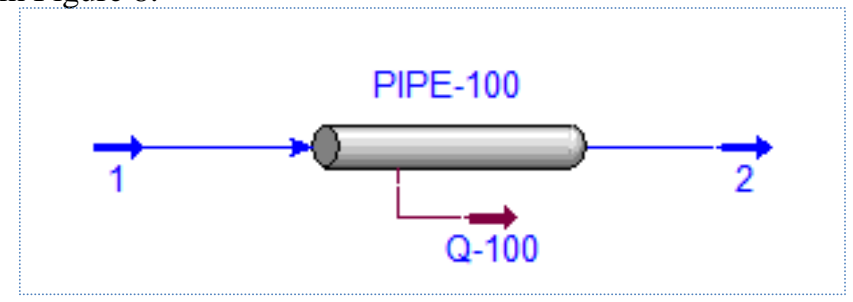

Figure 8. HYSYS model of pipeline transportation

\subsection{Effect of ambient temperature on the formation of hydrate}

In the process of transporting $\mathrm{CO}_{2}$ through a pipeline, the environment temperature directly affects the temperature, pressure and the formation of $\mathrm{CO}_{2}$ hydrate along the pipeline. By using HYSYS software, the change of each parameter in the process of $\mathrm{CO}_{2}$ pipeline transmission under different operation conditions is simulated, as shown in Figures 9 to 12. 


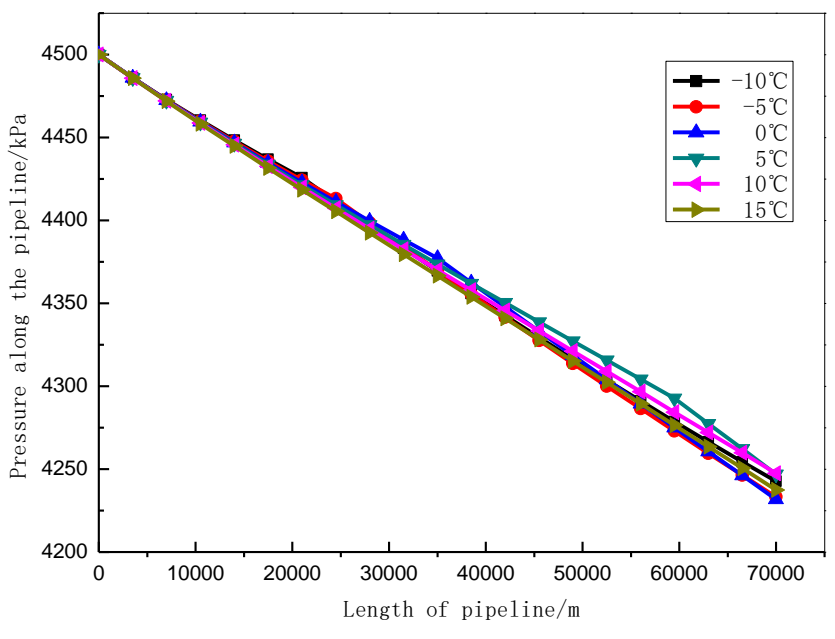

Figure 9. Pressure graph aong the length of the pipeline

From Figure 9, we can see that in the $\mathrm{CO}_{2}$ gas transmission pipeline under the initial pressure of $4500 \mathrm{MPa}$, without considering the influence of the elevation, the trend of the pressure along the pipeline is basically the same for different ambient temperatures. For a length of $70 \mathrm{~km}$ pipeline, outlet pressure is $4250 \mathrm{Mpa}$.

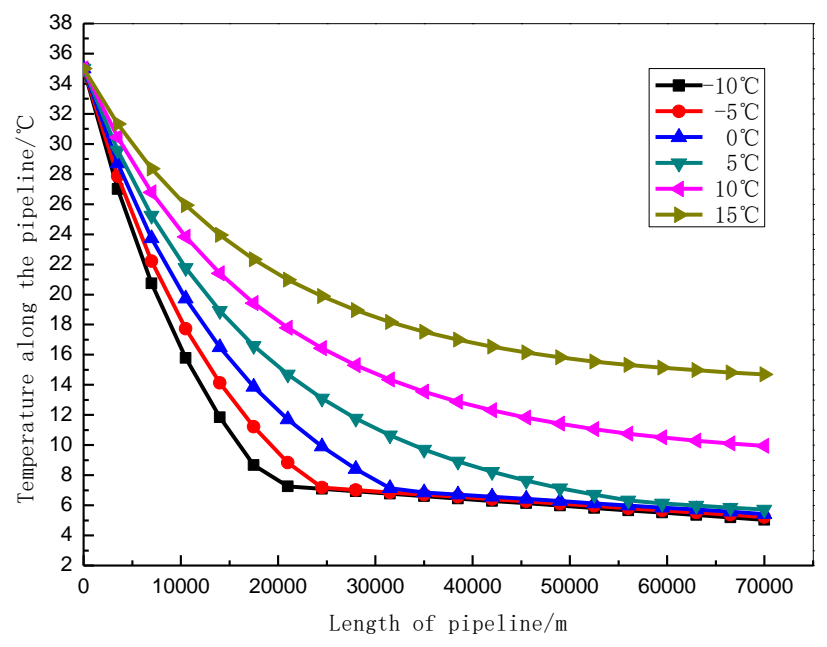

Figure 10. Temperature graph along the length of the pipeline

From Figure 10, we can see that in the $\mathrm{CO}_{2}$ gas transmission pipeline at the initial temperature of $35{ }^{\circ} \mathrm{C}$, without considering the influence of heat level, temperature drops along the pipeline are strongly influenced by the ambient temperature. The lower the ambient temperature is, the greater the temperature drops along the pipeline. And when the ambient temperature is low, the phase change will occur in the pipeline; $\mathrm{CO}_{2}$ changes from the gas state to the liquid state. Phase transition will increase the energy consumption during the process, and also will cause security risks. Therefore, in the case of low ambient temperature, the thickness of the insulation layer should be increased or heating equipment is required.

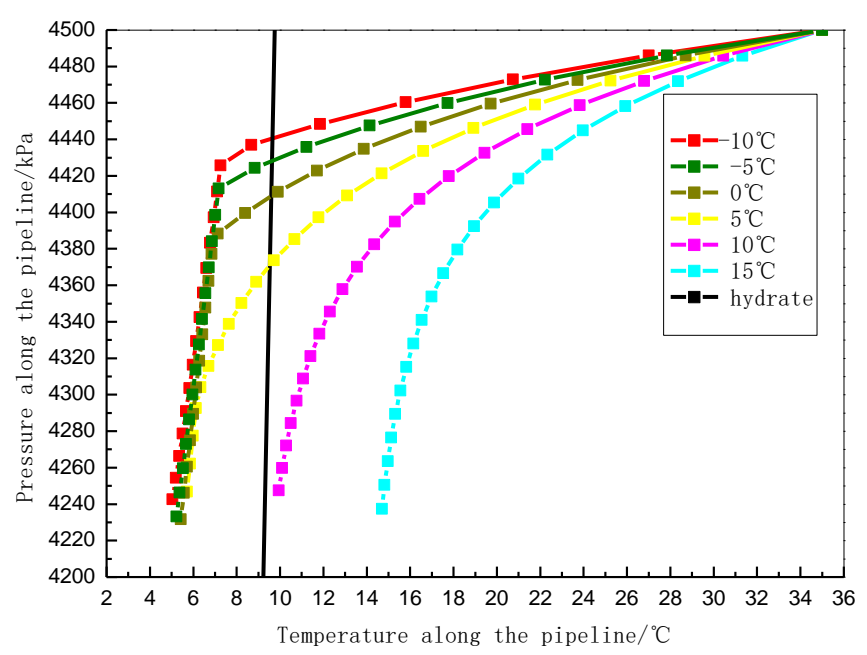

Figure 11. Generating point of hydrate along the pipeline

Figure 11 shows that when the ambient temperature is relatively low, the $\mathrm{CO}_{2}$ hydrate will be generated in the process of transportation. When the ambient temperature is higher than $10^{\circ} \mathrm{C}$, the hydrate will not be formed in the pipeline and the phase shift from gas to liquid will not occur. Therefore, there is no need to heat in the process of transportation when the environment temperature is higher than $10^{\circ} \mathrm{C}$.

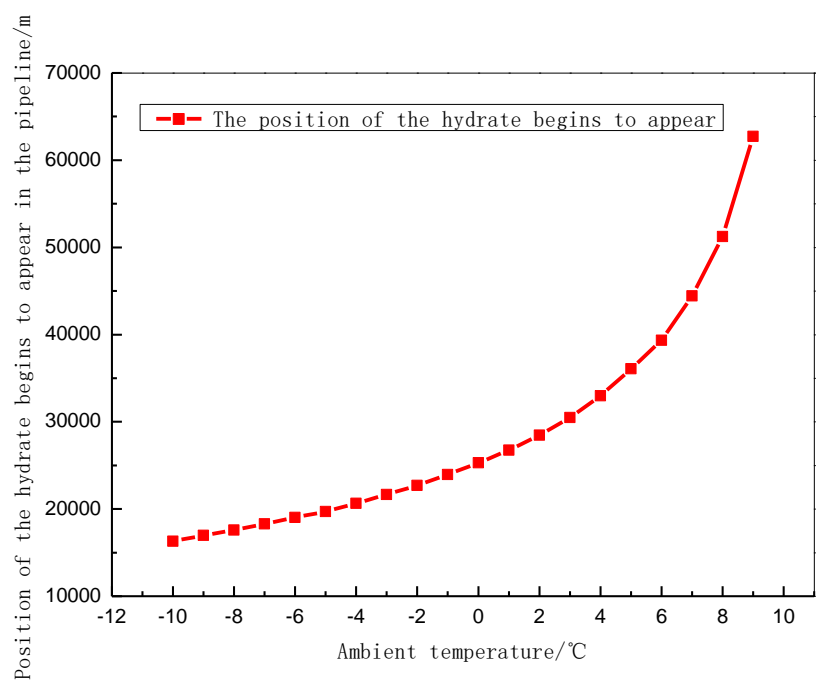

Figure 12. Relationship between ambient temperature and the location of the gas hydrate in the pipeline

Figure 12 shows that when the ambient temperature is relatively low, the hydrates will appear at about $16 \mathrm{~km}$ from the start of the pipeline. And when the ambient temperature is low, the position of the hydrates changes slowly with the environment temperature. When the ambient temperature is higher than about $4{ }^{\circ} \mathrm{C}$, the position of the hydrates changes relatively fast with the environmental temperature. When the ambient temperature is higher than about $10^{\circ} \mathrm{C}$, there will be no hydrates in the pipeline.

\section{CONCLUSION}

By comparing the experimental results with the simulation 
results of HYSYS, the feasibility of the HYSYS simulation has been demonstrated. Based on this, the influence of impurities on the formation of $\mathrm{CO}_{2}$ hydrates and the various operation conditions in the process of $\mathrm{CO}_{2}$ pipeline transportation are simulated. The following conclusions can be obtained:

(1) It is feasible to select P-R state equation to predict $\mathrm{CO}_{2}$ hydrate in HYSYS.

(2) Gas impurities such as $\mathrm{CH}_{4}, \mathrm{~N}_{2}, \mathrm{H}_{2}, \mathrm{O}_{2}$ and other gases have a small influence on the formation of $\mathrm{CO}_{2}$ hydrates.

(3) In the process of gas $\mathrm{CO}_{2}$ pipeline transportation, the ambient temperature has a small influence on the pressure of the pipeline. With a change in ambient temperature, the temperature along the pipeline changes greatly. $\mathrm{CO}_{2}$ will change from a gas state to a liquid state when the ambient temperature is low. In the case of low ambient temperature, a thick layer of insulation should be used and heating of the pipeline may also be required. When the ambient temperature is higher than about $10^{\circ} \mathrm{C}$, there will be no hydrates formed in the pipeline.

\section{ACKNOWLEDGMENT}

The authors gratefully expressed their thanks for the financial support for this research from the National Natural Science Foundation of China (no. 51306022), from the National Natural Science Foundation of Hubei Province (no. 2013CFB398), from the Science and Technology Innovation Foundation of PetroChina (no. 2015D-5006-0603) and from the Yangtze Youth Talents Fund (No. 2015cqt01).

\section{REFERENCES}

[1] Kim Johnsen and Kaare Helle, "DNV Recommended practice: Design and operation of $\mathrm{CO}_{2}$ pipelines," Energy Procedia, vol. 4, pp. 3032-3039, 2010. DOI: 10.1016/j.egypro.2011.02.214.

[2] Seo Y, Huh C and Chang D, "Economic evaluation of $\mathrm{CO}_{2}$ liquefaction processes for ship-based Carbon Capture and Storage (CCS) chain," Nature, vol. 333, no. 6170, pp. 209-210, 2014.

[3] Clair Gough, Laura O'Keefe and Sarah Mander. (2014, Jul.). Public perceptions of $\mathrm{CO}_{2}$ transportation in pipelines. Energy Policy. [Online]. vol. 70. pp. 106-114. Available:

http://dx.doi.org/10.1016/j.enpol.2014.03.039.

[4] Hui Jian, Liu Jianyi, Ye Changqing, et al., "Smulation and Prediction of Hydrate Formation under the Conditions of high Carbon Dioxide Content," Joumal of Southwest Petroleum University, vol. 29, no. 2, pp. 14-16, 2007.

[5] Luo Wei. "Research on the natural gas with high content of $\mathrm{CO}_{2}$ pipeline transportation technology," Ph.D. dissertation, Dept. Oil\&Gas. Eng. Southwest Petroleum Univ., Chengdu, China, 2013.

[6] Liu Jianwu. "Key issues related to engineering design of $\mathrm{CO}_{2}$ transportation pipeline", Oil\&GasStorage and Transportation, vol.33, no. 4, pp. 369-373, 2014. DOI: 10.6047/j.issn.1000-8241.2014.04.006.

[7] Gong Zhiwu, Zhang Liang, Cheng Haiqing, et al., "The influence of subsea natural gas hydrate dissociation on the safety of offshore drilling," Petroleum Drilling Techniques, vol. 43, no. 4, pp. 19-24, 2015. DOI: 10.11911/syztjs.201504004.

[8] Song Zhonghua, Zhang Shicheng, Wang Tengfei, et al. "Downhole throttling technology for gas hydrate prevention in deep gas wells of Tarim Oilfied," Petroleum Drilling Techniques, vol. 42, no. 2, pp. 9196, 2014. DOI: $10.3969 /$ j.issn.1001-0890.2014.02.018.

[9] Li Yuxing, Liu Mengshi, Zhang Jian. "Impacts of gas impurities on the security of $\mathrm{CO}_{2}$ pipeline," Natural Gas Industry, vol. 34, no. 1, pp. 108-113, 2014. DOI: 10.3787/j.issn.1000-0976.2014.01.017.

[10] Zhao Qing and Li Yuxing, "Impact of impurities on the phase behavior of $\mathrm{CO}_{2}$ in pipeline transportation," Oil \& Gas Storage and Transportation, vol. 33, no. 07, pp. 734-739, 2014. DOI: $10.6047 / \mathrm{j}$. issn.10008241.2014.07.010.

[11] Tang Cuiping, Zhao Xiangyong, He Yong et al., "Study on $\mathrm{CO}_{2}$ gas hydrate formation and flow characteristics in pipe," Natural Gas Chemical Industry, vol. 40, no. 4, pp. 37-40, 2015.

[12] Wu Xia, Li Changjun and Jia Wenlong. "Pipeline transportation technology of carbon dioxide," Oil-Gas Field Surface Engineering, vol. 29, no. 9, pp. 52-53, 2010. DOI: $10.3969 /$ j.issn.1006-6896.2010.09.024. 